\title{
Peningkatan Kapasitas Kader Posyandu Melalui Pelatihan Pemantauan Pertumbuhan dan Perkembangan Balita di Wilayah Kerja Puskesmas Kereng Bangkirai Kecamatan Sebangau Palangka Raya
}

\author{
Capacity Building for Posyandu Cadres through Training on Monitoring Growth and \\ Development of Toddlers in the Working Area of Puskesmas Kereng Bangkirai, Sebangau \\ District, Palangka Raya
}

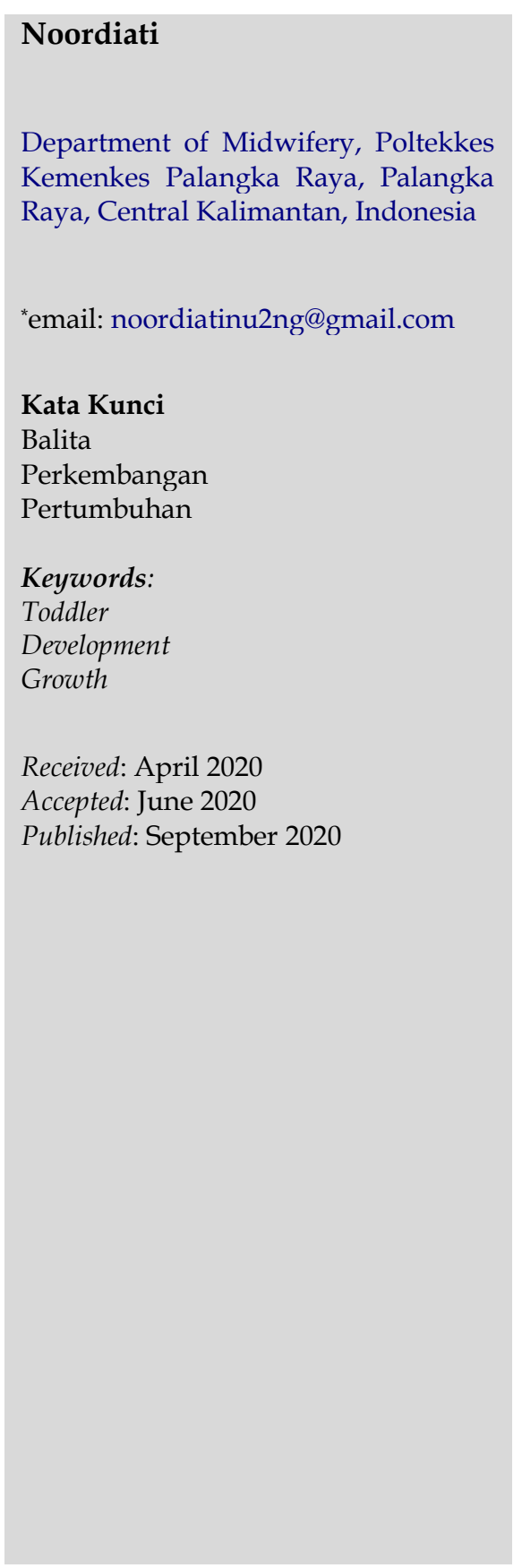

\begin{abstract}
Abstrak
Upaya pemantauan tumbuh kembang anak usia dini merupakan tugas keluarga, namun tidak semua keluarga dapat melaksanakan tugas tersebut secara optimal. Kesibukan, kurangnya pengetahuan dan keadaan sosial ekonomi keluarga menjadi faktor yang tidak mendukung upaya tersebut. Oleh karena itu pemantauan pertumbuhan anak dikoordinasikan melalui peran masyarakat melalui program Posyandu. Posyandu sebagai salah satu upaya kesehatan bersumber daya masyarakat memiliki peran vital untuk memberikan kemudahan kepada masyarakat dalam memperoleh pelayanan dasar. Untuk mencapai tujuan tersebut dibutuhkan peran seorang kader Posyandu yang memiliki pengetahuan dan keterampilan dalam melakukan pemantauan pertumbuhan dan perkembangan anak. Metode kegiatan dilaksanakan dengan cara pemberian materi tumbuh kembang anak dan praktikum cara penilaian dan pengukuran tumbuh kembang anak. Hasil kegiatan diukur melalui perbedaan hasil pre-tes dan post-test, serta hasil pengamatan ketika kader memberikan pelayanan saat pelaksanaan Posyandu. Hasil kegiatan menunjukkan pelatihan pemantauan pertumbuhan dan perkembangan anak balita yang diberikan kepada kader Posyandu dapat meningkatkan pengetahuan dan keterampilan kader dalam memberikan pelayanan di Posyandu terkait pemantauan pertumbuhan dan perkembangan anak balita.
\end{abstract}

\begin{abstract}
Monitoring the development of early childhood is a family task, but not all families can carry out this task optimally. Busyness, lack of knowledge, and the socio-economic condition of the family are factors that do not support this effort. Therefore, monitoring children's growth is coordinated through the role of the community through the Posyandu program. Posyandu, as one of the community-based health efforts, has a vital role in providing convenience to the community in obtaining essential services. To achieve this goal requires the role of a Posyandu cadre who has the knowledge and skills in monitoring child growth and development. The method of activity is carried out by providing material for child development and practicum on how to assess and measure children's growth and development. The results of activities were measured through differences in the results of the pre-test and post-test, as well as the results of observations when cadres provided services during Posyandu implementation. The results of the activity showed that the training in monitoring the growth and development of children under five given to Posyandu cadres could increase the knowledge and skills of cadres in providing services at Posyandu related to monitoring the growth and development of children under five.
\end{abstract}




\section{PENDAHULUAN}

Pada periode 2015-2019 pembangunan kesehatan memfokuskan pada Program Indonesia Sehat dengan sasaran meningkatkan derajat kesehatan dan status gizi masyarakat. Sasaran tersebut dilakukan melalui upaya kesehatan dan pemberdayaan masyarakat yang didukung dengan perlindungan finansial pemerataan pelayanan kesehatan (Marwati et al., 2018). Rencana Pembangunan Jangka Menengah Nasional 2015-2019 diantaranya adalah meningkatkan status kesehatan dan gizi ibu dan anak, meningkatnya pengendalian penyakit, meningkatnya akses dan mutu pelayanan kesehatan dasar dan rujukan terutama di daerah terpencil, tertinggal dan perbatasan, meningkatnya cakupan pelayanan kesehatan universal melalui Kartu Indonesia Sehat dan kualitas pengelolaan SJSN Kesehatan, terpenuhinya kebutuhan tenaga kesehatan, obat dan vaksin, serta meningkatkan responsivitas system kesehatan (Kementerian Kesehatan Republik Indonesia, 2015).

Diantara upaya pembangunan manusia seutuhnya adalah pembangunan kesehatan, yang diselenggarakan dalam bentuk upaya kesehatan anak sejak dini mulai dari dalam kandungan ibunya (Saepuddin et al., 2017). Untuk menghasilkan keturunan yang lahir dengan sehat dan selamat (intact survival), upaya kesehatan ibu dilakukan sebelum dan semasa hamil sampai persalinan (Saadah, 2016). Kelangsungan hidup anak perlu dipertahankan demikian juga dengan kualitas hidup anak agar tercapai tumbuh kembang yang optimal baik fisik, mental, emosional maupun social, dan diharapkan memiliki intelegensi majemuk sesuai dengan potensi genetiknya. Agar hal tersebut dapat dicapai maka upaya kesehatan dilakukan sejak anak masih dalam kandungan sampai lima tahun pertama kehidupannya (Kementerian Kesehatan Republik Indonesia, 2012).
Sebagai calon generasi penerus bangsa dengan jumlah yang besar di Indonesia yaitu sekitar 10\% dari seluruh populasi, kualitas tumbuh kembang balita di Indonesia perlu mendapatkan perhatian yang serius (Putri et al., 2018). Yang dibutuhkan oleh balita adalah mendapatkan gizi yang baik, stimulasi yang memadai serta terjangkau oleh pelayanan yang berkualitas termasuk deteksi dan intervensi dini penyimpangan petumbuhan dan perkembangan anak. Faktor lingkungan yang dapat mengganggu tumbuh kembang anak juga merupakan hal yang perlu di eliminasi (Kementerian Kesehatan Republik Indonesia, 2012).

Keluarga merupakan lingkungan terdekat dengan anak yang mengetahui dengan pasti perjalanan tumbuh kembang anak. Anak menghabiskan waktu dalam lingkungan yang disebut keluarga. Anggota keluarga adalah yang pertama kali bersentuhan dengan anak sejak dilahirkan. Lingkungan terdekat tempat anak mulai belajar adalah anggota keluarga dengan mengamati perilaku anggota keluarga (Alia \& Irwansyah, 2018). Yang menjadi permasalahan adalah tidak semua keluarga dapat melaksanakan tugas pemantauan pertumbuhan dan perkembangan anak secara optimal. Beberapa faktor yang tidak mendukung upaya pemantauan tumbuh kembang anak usia dini diantaranya adalah kesibukan, kurangnya pengetahuan, dan keadaan social ekonomi keluarga, padahal seharusnya secara pokok tugas pemantauan ini secara pokok merupakan tugas keluarga. Oleh karena itu, pemantauain pertumbuhan dan perkembangan anak dikoordinasikan melalui peran masyarakat melalui program Posyandu (Hayati et al., 2015).

Fungsi Posyandu adalah sebagai wadah pemberdayaan masyarakat dalam alih informasi dan keterampilan kepada masyarakat dari petugas kesehatan dan antar sesama masyarakat serta mendekatkan pelayanan kesehatan dasar, terutama yang berkaitan dengan 
Angka Kematian Ibu, Angka Kematian Bayi dan Angka Kematian Balita (Cahyati et al., 2019). Di Indonesia tersebar Posyandu sekitar 266.872 buah, setiap Posyandu terdapat sekitar 3 sampai 4 orang kader yang berarti jika dihitung akan terdapat lebih dari 1 juta orang (Tse et al., 2017).

Keberhasilan suatu Posyandu sangat tergantung dari kerja keras kader yang dengan sukarela mengelola Posyandu yang ada di wilayahnya masing-masing (Simanjuntak, 2012). Faktor yang dapat menyebabkan kurangnya pemahaman terhadap tugas kader, lemahnya informasi serta kurangnya koordinasi antara petugas dengan kader dalam pelaksanaan kegiatan posyandu dapat mengakibatkan rendahnya tingkat kehadiran Balita ke Posyandu. Hal ini dapat disebabkan oleh kurangnya pelatihan dan pembinaan untuk meningkatkan keterampilan yang memadai bagi kader. Hal ini juga akan berimbas pada rendahnya cakupan deteksi dini tumbuh kembang balita (Sayuthi \& Ridwan, 2016).

Puskesmas Kereng Bangkirai merupakan salah satu Puskesmas yang ada di Kota Palangka Raya yang memiliki 13 posyandu dengan cakupan balita terbanyak dibanding Puskesmas lainnya yang ada di Kota Palangka Raya. Dari 13 Posyandu yang ada, dipilih 2 Posyandu yaitu Posyandu Panenga dan Posyandu Permata Hati yang memiliki potensi menjadi posyandu aktif dan berkembang, namun dari studi pendahuluan yang dilakukan, 10 orang kader dari posyandu tersebut belum pernah mendapatkan informasi yang memadai mengenai pemantauan pertumbuhan dan perkembangan, sehingga dalam melaksanakan tugasnya sebagai kader hanya bermodalkan pengetahuan yang kurang.

Secara umum kegiatan pengabdian ini bertujuan agar semua balita tumbuh dan berkembang secara optimal sesuai dengan potensi genetikanya sehingga berguna bagi nusa dan bangsa serta mampu bersaing di era global melalui kegiatan pemantauan tumbuh kembang anak. Secara khusus betujuan meningkatkan jumlah kader Posyandu yang bisa melakukan pemantauan pertumbuhan dan perkembangan anak, menigkatkan jumlah balita yang terpantau pertumbuhan dan perkembangannya dan meningkatkan jumlah balita tumbuh dan berkembang secara optimal sesuai potensi masing-masing.

\section{METODOLOGI}

Sasaran kegiatan adalah Kader Posyandu yang ada di Wilayah Kerja Puskesmas Kereng Bangkirai, untuk kegiatan ini diambil 10 orang Kader yang dinilai aktif mengikuti kegiatan Posyandu yang berasal dari Posyandu Panenga dan Posyandu Permata Hati.

Sarana yang digunakan untuk meningkatkan kapasitas Kader Posyandu adalah Balai desa yang biasa digunakan sebagai tempat pelayanan Posyandu setiap bulan, Klinik Praktik Mandiri Bidan S yang digunakan sebagai tempat pelatihan. Alat dan bahan yang digunakan adalah Lembar balik kelas Ibu Balita, Buku KIA, Peraga KMS, dan buku pedoman pelaksanaan SDIDTK untuk pelayanan dasar.

Metode kegiatan yang digunakan berdasarkan hal-hal berikut ini, yaitu: Berdasarkan masalah (Problem Based), yakni proses peningkatan kapasitas keder didekatkan pada masalah nyata yang ada dilapangan.

Berdasarkan kompetensi (Competency Based), berupaya untuk mengembangkan keterampilan berjenjang langkah demi langkah menuju kemampuan paripurna. Pembelajaran orang dewasa (Adult Learning) proses peningkatan kapasitas kader diselenggarakan dengan pendekatan pembelajaran orang dewasa, dimana peserta berhak untuk didengarkan dan dihargai pengalamannya, dan dipertimbangkan setiap ide dan pendapat sejauh berada dalam konteks pelatihan serta 
dihargai keberadaannya. Pembelajaran dengan melakukan (Learning by Doing), memungkinkan peserta berkesempatan melakukan eksperimentasi dari materi pelatihan dengan menggunakan metode pembelajaran antara lain diskusi kelompok, studi kasus, simulasi dan latihan baik secara individu maupun kelompok, dan melakukan pengulangan atau perbaikan yang dirasa perlu. Kegiatan dilaksanakan dalam empat sesi yaitu:

\section{Sesi Pertama}

Dimulai dengan penjajakan awal peserta dengan memberikan tes awal (pre-test) berisi 15 pertanyaan terkait pengertian, penilaian, pencatatan, dan penyimpangan petumbuhan dan perkembangan anak. Dilanjutkan dengan penyampaian materi mengenai pengertian pertumbuhan dan perkembangan, faktor yang mempengaruhi kualitas pertumbuhan dan perkembangan anak, serta tahapan tumbuh kembang anak. Diharapkan dengan materi yang diberikan, kader dapat memahami konsep pertumbuhan dan perkembangan anak.

2. Sesi kedua

Dengan memberikan materi mengenai penyimpangan pertumbuhan dan perkembangan anak, cara melakukan deteksi penyimpangan pertumbuhan dan perkembangan anak, serta pengenalan instrument yang digunakan untuk mendeteksi pertumbuhan dan perkembangan anak.

3. Sesi ketiga

Bertepatan dengan pelaksanaan Posyandu Panenga. Review semua materi baik teori maupun praktik untuk memantapkan pengetahuan dan keterampilan peserta. Kader didampingi melaksanakan kegiatan di posyandu, diantaranya pengukuran dan penilaian pertumbuhan dan perkembangan serta pengisian instrument dan pencatatan.
4. Sesi keempat

Dilakukan evaluasi terhadap pelaksanaan penilaian pertumbuhan dan perkembangan anak saat pelaksanaan posyandu. Pada akhir sesi dilaksanakan post tes untuk menilai perubahan pengetahuan dan keberhasilan pencapaian kompetensi yang didapat setelah mengikuti pelatihan.

\section{HASIL DAN PEMBAHASAN}

Sebagian besar Kader Posyandu yang mendapatkan peningkatan kapasitas mengenai pertumbuhan dan perkembangan anak berusia di atas 30 Tahun yaitu sebanyak 70\%, dan selebihya berusia kurang dari 30 Tahun sebanyak $10 \%$ dan di atas 40 Tahun sebanyak $20 \%$. Karakteristik peserta peningkatan kapasitas kader posyandu berdasarkan umur dapat dilihat pada Gambar 1.

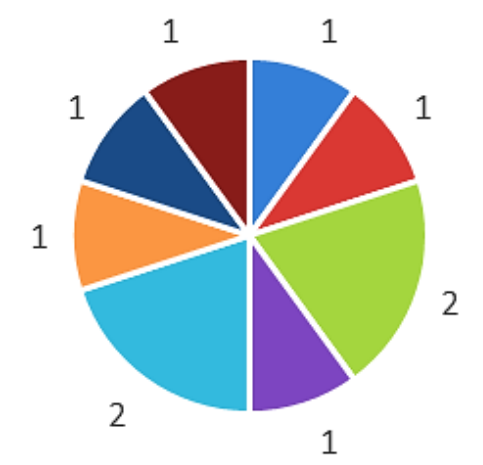

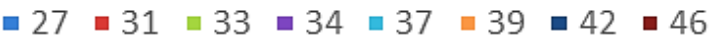

Gambar 1. Karakteristik Kader Berdasarkan Umur (Tahun)

Sebagian besar Kader Posyandu memiliki pengalaman menjadi Kader selama 1 Tahun yaitu sebanyak 50\%, yang memiliki pengalaman selama 2 Tahun sebanyak $20 \%$ dan sisanya memiliki pengalaman menjadi Kader Posyandu selama 5 Tahun dan 10 Tahun masing-masing sebanyak 10\%. Karakteristik peserta peningkatan kapasitas kader posyandu berdasarkan lama pengalaman bekerja dapat dilihat pada Gambar 2 . 


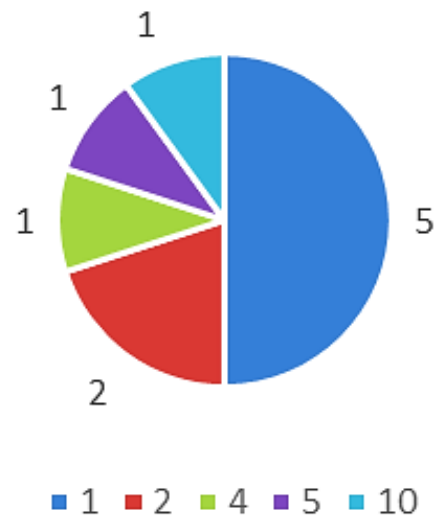

Gambar 2. Karakteristik Kader Berdasarkan lama pengalaman bekerja (Tahun)

Sebelum pelatihan dilaksanakan, terlebih dahulu dilakukan diskusi dengan kader yang bertujuan untuk mengetahuan gambaran pengetahuan dan keterampilan awal yang dimiliki oleh kader posyandu. Hasil diskusi ini menjadi acuan dalam menentukan materi ajar yang diberikan saat pelaksanaan pelatihan, dengan harapan materi dan keterampilan yang diberikan dapat memberikan mafaat bagi kader posyandu. Hal ini sesuai dengan pendapat (Paramita \& Kristiana, 2013) bahwa diskusi kelompok terarah bertujuan untuk mengetahui gambaran tingkat pengetahuan dan keterampilan serta persepsi, opini dan sikap kader. Hasil evaluasi skor pengetahuan sebelum dan sesuah berdasarkan data pada Tabel I menunjukkan bahwa terjadi peningkatan skor pengetahuan kader antara sebelum dan sesudah diberikan pelatihan sebesar rata-rata 3 skor.

Tabel I. Skor Pengetahuan Kader

\begin{tabular}{lcccc}
\hline \multicolumn{1}{c}{ Variabel } & n & Rata-rata & Min. & Max. \\
\hline Pengetahuan & & & & \\
-Sebelum & 10 & 5,5 & 4 & 6 \\
-Sesudah & 10 & 5,5 & 7 & 10 \\
\hline
\end{tabular}

Dari hasil diskusi diketahui beberapa hal diantaranya kader posyandu belum memiliki pengetahuan dan keterampilan yang baik mengenai cara penimbangan dan pengukuran tinggi/panjang badan anak serta cara menilai perkembangan anak dan cara menentukan jika terjadi penyimpangan pada pertumbuhan dan perkembangan anak. Pengisian KMS pada buku KIA belum diisi dengan benar sesuai petunjuk teknis pengisian KMS. Meja 4 dalam pelaksanaan Posyandu belum terlaksana. Belum adanya buku pegangan yang dapat dijadikan acuan atau pedoman dalam melaksanakan penimbangan, pengukuran tinggi/panjang badan, penilaian perkembangan dan hasil interpretasinya.

Materi yang diberikan kepada kader posyandu adalah mengenai pengertian dan perbedaan pertumbuhan dan perkembangan anak balita, dilanjutkan dengan teori pengukuran berat badan, pengukuran tinggi/panjang badan, interpretasi dari hasil pengukuran pertumbuhan anak, penilaian menggunakan Kuisioner Pra Skrining Perkembangan (KPSP), penilaian penyimpangan pertumbuhan dan perkembangan anak, dan tindak lanjut jika ditemukan penyimpangan terhadap pertumbuhan dan perkembangan anak.

Metode yang digunakan adalah kombinasi dari ceramah, tanya jawab, diskusi dan studi kasus. Hal ini sesuai dengan karakteristik pembelajaran orang dewasa yaitu pembelajaran lebih mengarah ke suatu proses pendewasaan, karena prinsip utama adalah memperoleh pemahaman dan kematangan diri, maka pembelajaran lebih utama menggunakan eksperimen, diskusi, pemecahan masalah, latihan, simulasi dan praktik lapangan. Orang dewasa akan siap belajar jika materi latihnya sesuai dengan apa yang ia rasakan sangat penting dan pengembangan kemampuan diorientasikan belajar terpusat pada kegiatannya (Sunhaji, 2013).

Berdasarkan hasil evaluasi terhadap pengetahuan yang dimiliki oleh kader posyandu sebelum dan sesudah pelatihan, terdapat peningkatan pengetahuan sebesar 3 . Hasil ini sejalan dengan dengan studi lain (Zaki et al., 2018) bahwa terdapat peningkatan skor sebesar 1,8 setelah mendapatkan pelatihan mengenai status gizi balita. Peningkatan pengetahuan ini bisa disebabkan 
oleh metode yang digunakan yaitu kombinasi antara metode konvensional ceramah, simulasi dan studi kasus (Retnawati et al., 2014).

Perubahan pengetahuan kader posyandu dapat juga disebabkan oleh latar belakang pendidikan yang dimiliki kader, hampir seluruh kader memiliki pendidikan tinggi (SMA dan Sarjana). Hal ini sesuai dengan pendapat (Tristanti \& Risnawati, 2017) bahwa pendidikan juga dapat mempengaruhi seseorang dalam berperilaku dan bersikap. Pada umumnya semakin tinggi pendidikan seseorang semakin mudah menerima informasi, sehingga diharapkan seseorang dengan pendidikan tinggi akan memiliki pengetahuan yang lebih baik.

Penilaian keterampilan awal kader posyandu dilakukan dengan observasi saat kader melakukan pelayanan di posyandu. Keterampilan yang dinilai adalah mengukur berat badan, mengukur tinggi/panjang badan dan pengisian KMS. Dari hasil pengamatan, hampir semua kader memiliki keterampilan yang benar saat melakukan penimbangan berat badan, namun keterampilan tergolong salah saat kader melakukan pegukuran tinggi/panjang badan, dan penilaian perkembangan anak. Demikian juga saat melakukan pengisian KMS, didapat hasil kurang cermatnya kader dalam pengisian data berat badan anak di kolom berat badan dan pengisian status naik $(\mathrm{N})$ atau tidak naik $(\mathrm{T})$ pada kolom KMS. Kader juga tidak cermat dalam pengisian diagram kenaikan berat badan karena banyak titik yang tidak dihubungkan sehingga sulit diinterpretasikan saat membaca diagram pertumbuhan anak di KMS.

Peningkatan keterampilan dimulai dengan melatih cara pengukuran pertumbuhan anak dengan pengukuran Berat Badan Terhadap Tinggi Badan (BB/TB) untuk menentukan status gizi anak usia dibawah 5 tahun, apakah normal, kurus, sangat kurus atau gemuk, pengukuran Panjang Badan terhadap umur atau Tinggi
Badan terhadap umur $(\mathrm{PB} / \mathrm{U}$ atau $\mathrm{TB} / \mathrm{U})$ untuk menentukan status gizi anak, apakah normal, pendek atau sangat pendek dan pengukuran Indeks Massa Tubuh menurut Umur (IMT/U) untuk menentukan status gizi anak usia 5-6 tahun apakah anak sangat kurus, kurus, normal, gemuk atau obesitas (Nugraheni et al., 2018). Kader juga mempraktekkan cara pengisian KMS yang sesuai dengan petunjuk teknis yang diterbitkan oleh Kementerian Kesehatan.

Evaluasi dilakukan ketika dilaksanakan Posyandu. Seluruh kader bergantian melakukan pengukuran pertumbuhan pada balita yang berbeda yang datang ke Posyandu. Berdasarkan hasil pengamatan, terjadi peningkatan keterampilan, yaitu hampir seluruh kader malakukan pengukura pertumbuhan dengan baik dan benar. Demikian juga dengan pengisian KMS, hampir seluruh kader dapat mengisi KMS dengan benar. Kelengkapan pengisian KMS ditinjau dari sembilan aspek, antara lain: kelengkapan pengisian biodata atau identitas diri anak, ketepatan memilih KMS berdasarkan jenis kelamin anak, ketepatan pengisian hasil timbangan, ketepatan mengisi titik berat badan pada diagram/kurva pertumbuhan, kelengkapan mengisi berat badan anak di setiap bulannya, kelengkapan pengisian keadaan kesehatan anak setiap bulan, kelengkapan mengisi keadaan naik atau tidak naik pada KMS, kelengkapan pengisian ASI eksklusif, kelengkapan pengisian imunisasi dan kelengkapan pengisian pemberian vitamin $\mathrm{A}$.

Penilaian perkembangan anak tidak sepenuhnya dapat dilakukan di Posyandu, mengingat tempat, fasilitas dan waktu yang tersedia saat pelaksanaan Posyandu. Namun setidaknya kader sudah memiliki keterampilan yang dapat dibagikan kepada orang tua mengenai cara penilaian perkembangan anak menggunakan Kuesioner Pra Skrining Perkembangan Anak (KPSP). 
Hal ini sesuai dengan studi lain bahwa terjadi peningkatan keterampilan dari 0,103 menajdi 0,427 antara pretest dan post test, yang berarti bahwa pelatihan dapat meningkatkan pengetahuan dan keterampilan kader (Evita et al., 2016). Dokumentasi kegiatan latihan pengisian KMS disajikan pada Gambar 3.

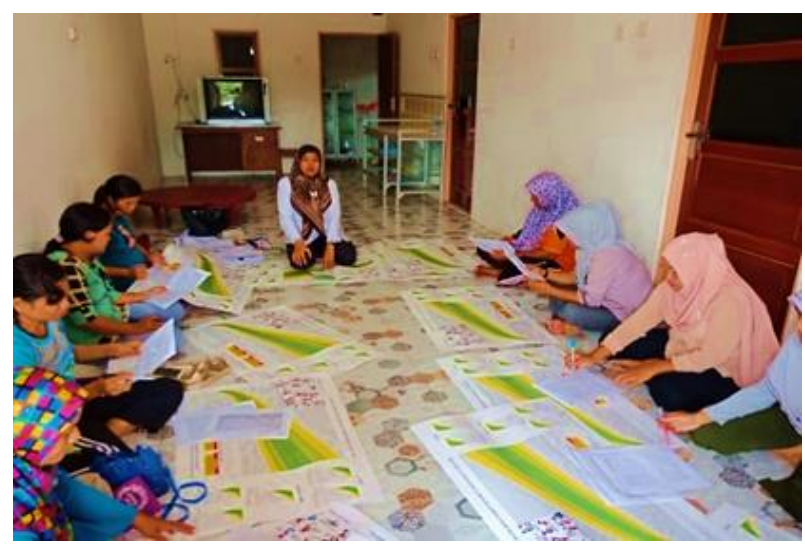

Gambar 3. Latihan Pengisian KMS

\section{KESIMPULAN}

Pelatihan pemantauan pertumbuhan dan perkembangan anak balita yang diberikan kepada kader posyandu dapat meningkatkan pengetahuan dan keterampilan kader dalam memberikan pelayanan di posyandu terutama terkait pemantauan pertumbuhan dan perkembangan anak balita. Hendaknya kegiatan serupa yang dilakukan kembali untuk meningkatkan pengetahuan dan keterampilan kader posyandu mengenai pertumbuhan dan perkembangan anak, mengingat sebagian besar kader dalam memberikan pelayanan di posyandu dengan pengetahuan dan keterampilan yang masih kurang.

\section{UCAPAN TERIMA KASIH}

Terima kasih kepada Kepala Dinas Kesehatan Kota Palangka Raya yang memberikan izin pelaksanaan pengabdian kepada masyarakat di wilayah kerja Dinas Kesehatan Kota Palangka Raya. Kepala Puskesmas Kereng Bangkirai selaku penanggung jawab kegiatan di wilayah kerja Puskesmas Kereng Bangkirai. Bidan pengelola Posyandu Panenga dan Posyandu Permata Hati. Mahasiswa Prodi D-III Kebidanan Semester V yang membantu pendapingan saat pelaksanaan praktik di Posyandu dan studi kasus saat pelatihan. Kader Posyandu Panenga dan Posyandu Permata Hati yang menjadi peserta peningkatan Kapasitas Kader Posyandu mengenai Pertumbuhan dan Perkembangan Anak.

\section{REFERENSI}

Alia, T., Irwansyah. 2018. Pendampingan Orang Tua Pada Anak Usia Dini Dalam Penggunaan Teknologi Digital. Polyglot: Jurnal Ilmiah. 14(1):65-78. http://dx.doi.org/10.19166/pji.v14i1.639

Cahyati, A., Februanti, S., Hidayat, U.A. 2019. Pelatihan Kader Posyandu di Wilayah Kelurahan Kersanegara Kecamatan Cibeureum Tasikmalaya. Abdimas Umtas : Jurnal Pengabdian kepada Masyarakat. 2(1):99-102. https://doi.org/10.35568/abdimas.v2i1.303

Evita, D., Mursyid, A., Siswati, T. 2013. Pelatihan meningkatkan pengetahuan dan keterampilan kader puskesmas dalam penerapan standar pemantauan pertumbuhan balita di Kota Bitung. Jurnal Gizi dan Dietetik Indonesia (Indonesian Journal of Nutrition and Dietetics). 1(1):15-21. http://dx.doi.org/10.21927/ijnd.2013.1(1).1521

Hayati, N., Muthmainnah, Fatimaningrum, A.S. 2015. Pelatihan Kader Posyandu Dalam Deteksi Perkembangan Anak Usia Dini. Jurnal Pendidikan Anak. 4(2):651-658. https://doi.org/10.21831/jpa.v4i2.12359

Kementerian Kesehatan Republik Indonesia. 2015. Rencana Strategis Kementerian Kesehatan Republik Indonesia 2015-2019. Jakarta: Kementerian Kesehatan Republik Indonesia.

Kementerian Kesehatan Republik Indonesia. 2012. Kurikulum dan Modul Pelatihan Posyandu. Jakarta: Kementerian Kesehatan Republik Indonesia.

Marwati, T., Aisya, I.R., Alifariani, A. 2018. Analisis Program Indonesia Sehat Dengan Pendekatan 
Keluarga (PIS-PK) Indikator Hipertensi dan KB di Desa Combongan RT 01, RT 02 dan RT 03. Jurnal Pemberdayaan: Publikasi Hasil Pengabdian Kepada Masyarakat. 2(1):75-82. https://doi.org/10.12928/jp.v2i1.487

Nugraheni, S.A., Aruben, R., Prihatini, I.S., Sari., Sulistyawati, E. 2018. Peningkatan Praktik Mandiri Ibu dalam Pemantauan Status Gizi Balita melalui Pendampingan Aktivitis Dasa Wisma. Media Kesehatan Masyarakat Indonesia. 14(4):418-428.

https://doi.org/10.30597/mkmi.v14i4.5233

Paramita, A., Kristiana, L. 2013. Teknik Focus Group Discussion dalam Penelitian Kualitatif. Buletin Penelitian Sistem Kesehatan. 16(2):117-127.

Putri, Y.R., Lazdia, W., Putri, L.O.E. 2018. Faktor yang Mempengaruhi Perkembangan Anak Balita Usia 1-2 Tahun di Kota Bukittinggi. Real in $\begin{array}{lll}\text { Nursing } \quad \text { 1(2):84-94. } & \end{array}$ http://dx.doi.org/10.32883/rnj.v1i2.264

Retnawati, S.A., Widajanti, L., Nugrahaeni, S.A. 2014. The Effect of Training by Simulation Method on Cadres to the Successfulness of Diversity Food Application (a Study in Kecamatan Trawas Kabupaten Mojokerto). Jurnal Manajemen Kesehatan Indonesia. 2(3):212-220. https://doi.org/10.14710/jmki.2.3.2014.\%25p

Saadah, E. 2016. Faktor-Faktor Yang Mempengaruhi Kepuasan Kerja Bidan Dan Implikasinya Terhadap Kinerja Bidan di DKI Jakarta. Kontigensi : Jurnal Ilmiah Manajemen. 3(2):129140.

Saepuddin, E., Rizal, E., Rusmana, A. 2017. Posyandu Roles as Mothers and Child Health Information Center. Record and Library Journal. 3(2):201-208.

http://dx.doi.org/10.20473/rlj.V3-

I2.2017.201-208

Sayuthi, M., Ridwan, A. 2016. Pengetahuan Dan Peran Kader Posyandu Tentang Gizi Balita Diwilayah Kerja Puskesmas Aceh Besar. Jurnal Ilmiah Mahasiswa (JIM) Fakultas Keperawatan. 1(1):1-8.

Simanjuntak, M. 2012. Karakteristik Sosial Demografi dan Faktor Pendorong Peningkatan Kinerja Kader Posyandu. Jurnal Wira Ekonomi Mikroskil: JWEM. 2(1):49-58.
Sunhaji, S. 2013. Konsep Pendidikan Orang Dewasa. Jurnal Kependidikan. 1(1):1-11. https://doi.org/10.24090/jk.v1i1.528

Tristanti, I., Risnawati, I. 2017. Motivasi Kader Dan Kelengkapan Pengisian Kartu Menuju Sehat Balita Di Kabupaten Kudus. Indonesia Jurnal Kebidanan. 1(1):1-11. http://dx.doi.org/10.26751/ijb.v1i1.221

Tse, A.D.P., Suprojo, A., Adiwidjaja, I. 2017. Peran Kader Posyandu Terhadap Pembangunan Kesehatan Masyarakat. IISIP: Jurnal Ilmu Sosial dan Ilmu Politik. 6(1):60-62.

Zaki, I., Farida, F., Sari, H.P. 2018. Peningkatan Kapasitas Kader Posyandu Melalui Pelatihan Pemantauan Status Gizi Balita. Jurnal Pengabdian Kepada Masyarakat (Indonesian Journal of Community Engagement). 3(2):169-177. https://doi.org/10.22146/jpkm.28595 